\title{
NORWEGIAN GLACIERS
}

G LACIOLOGICAL research at the present time consists of two main tasks: first, the recording of the state and behaviour of glaciers; and secondly, the study of the various factors controlling their behaviour. The latter normally progresses by intensive studies in limited areas or of specific problems. The general recording of glaciers and their behaviour requires widespread survey, mapping and a continued interest in glaciers and the surrounding country spread over many years. Adolf Hoel and the late Werner Werenskiold have had both broad and specific interests in the glaciers of Norway throughout their lives. In the Glaciological Bibliography of Norway* entries under Adolf Hoel are dated from 1906-56, and under Werner Werenskiold from 1913-61. Their lifetime interest and knowledge of Norwegian glaciers makes their general review of Glaciers and Snowfields in Norway $\dagger$ a work of authority and value. It is written in English, and will thus be useful to students in many countries.

The first section of Glaciers and Snowfields in Norway deals with the history of glaciological research in Norway, then lists the glaciers of Norway with details of their area. Dates of surveys are given, since it has not been possible to survey all glaciers contemporaneously. Data for southern Norway are mostly up to date (about 960 glaciers), but in northern Norway many surveys used were made around the beginning of this century, since when a marked recession may have decreased the area of glaciers by perhaps 30 per cent. However, dates are given and changes to the present day can be determined by field parties visiting these areas. The present senior glaciologist of the Norsk Polarinstitutt, Olav Liestol, has always been a ready guide and helper to those seeking advice on where mapping of the glaciers will be most useful, and this volume may stimulate further work.

Former glacier fluctuations are discussed in the light of indirect evidence, such as the preservation of arrowheads and ropes by ice, which indicates that snow and ice cover must have increased from at least A.D. 1500 until A.D. 1750, when a general recession commenced. Although some advance occurred in the period $1850-55$, it appears less marked than that in the European Alps. Spitsbergen glaciers are also discussed, where, apart from a general decrease in size in recent decades, some catastrophic advances, such as that which added $600 \mathrm{~km}^{2}$ to the area of Bråsvelbreen, are noted.

The section discussing benefits derived from glaciers starts naturally with their relations to hydroelectric power. Glaciers also provide useful lines of communica-tion of use between settlements as well as by tourists. Commercial exploitation of glacier ice is also covered. Collection by fishing vessels for refrigeration purposes was important for at loast thirty years up to 1949 near Oksfordjokulln, but other forms of export of ice, although pursued, were apparently less successful in this area.

The remaining 170 pages of the book presents a wealth of data on glaciers studied by Hoel, Werenskiold and their associated workers. Work in the Jotunheim area over the period 1927-48 covers surveys, accumulation, ablation, velocity, stream discharge and other measurements. Studies have concentrated especially on Hollstugubreen and Tverrabreen. Maps of both glaciers and a series of maps of Tverråbreen during 1927-38 are presented in a separate folder. Similar investigations on glaciers in northern Norway are presented.

The Glaciological Bibliography of Norway contains some 1,500 references to work on Norwegian glaciers presented both as a regional and as a chronological (author) catalogue. Its usefulness is increased by symbols denoting that the papers contain maps or photographs of special use for future comparisons. References are cited up to 1958 with some additions to 1961 .

All those interested in the study of Norwegian glaciers will benefit greatly by these publications, which not only draw together a considerable amount of scattered work, but also contain many sections which would interest anyone visiting these areas.

G. DE Q. ROBIN

* Norsk Polarinstitutt. (Det Kongelige Departement for Industri og Handverk.) Skrifter Nr. 126: Glaciological Bibliography of Norway. By Adolf Hoel and Johannes Norvik. Pp. 242. (Oslo:

$\dagger$ Norsk Polarinstitutt. (Det Kongelige Departement for Industri og Hand verk.) Skrifter Nr. 114: Glaciers and Snowfields in Norway. By Adolf Hoel and Werner Werenskiold. Pp. $291+8$ maps. (Oslo: Norsk Polar institutt. Distributed by Oslo University Press, 1962.) $40 \mathrm{Kr}$.

\section{FORAGING AND FEEDING BEHAVIOUR}

A SYMPOSIUM of the Society for the Study of Animal Behaviour held at the London Zoological Gardons during July 9-11 was devoted to the topic of "Foraging and Feeding Behaviour". Most of the papers read on the first day of the meeting dealt with insects and had an ecological rather than ethological flavour. F. Raw (Rothamsted Experimental Station) was more concerned with the aspects and effects of foliage disposal by earthworms than with the behavioural mechanisms operative in this remarkable affair, interest in which goes back to Darwin. "As fallen foliage in orchards harbours stages in the life-cycle of fruit tree pests its speedy disposal is an important factor in the health of the fruit trees." Leaf burial by earthworms (Lumbricus terrestris) is, therefore, of great potential ecological importance.

Barbara A. Hopkins (Ascot Field Station of the Imperial College of Science and Technology) reported on the "Probing Response of Stomoxys calcitrans (the Stable Fly) to Odours". Ammonia chiefly and a series of other components were offered to individual flies after and during a 24 -h period following a blood or sugar meal, and their proboscal probing was observed. Probing does not seem to be associated with need for water and shows no obvious $24 \mathrm{~h}$ or longer period rhythmicity. Its threshold also is unaffected by larval environment or crowding. This gradually fell during the $24 \mathrm{~h}$ after feeding. There is some evidence that receptors responsible for the probing sequence are located on the tarsi. $N$-propyl amine and several lower fatty acids approach ammonia in stimulating effect. A. J. Cockbain (Rothamsted) also dealt with probing in his paper on "The Probing and Feeding Behaviour of Alate Aphids in Relation to the Transmission of Some Plant Viruses". He showed that infectivity with non-persistent viruses such as pea and sugar beet mosaic virus is associated with short duration probing and not with prolonged feeding on infected plants. Many Myzus persicae individuals but few Aphis fabae probe for a short time (15-60 sec) before flying from infected plants on which they have been feoding. This may explain the difference in infectivity of the two species. $A$. fabae also seem to fail to insert their stylets into the plant tissues when probing. 
"The Feeding and Excretion Behaviour of Aphids" was analysed quantitatively by C. J. Banks (Rothamsted). He demonstrated that most aphids feed on the phloem tissues of the host plant. That they feed on the sieve tube elements has only rarely been convincingly demonstrated. It may take them as long as $14-16 \mathrm{~h}$ to reach the maximum rate of feeding. In this aphids do not seem to rely entirely on the sap pressures within the plant and there is some evidence for active sucking and relation of intake to need during post-reproductive ageing when excretion has stopped.

J. Sudd (Department of Zoology, Hull) analysed the behaviour involved in the transport of prey by ants and finds two chief mechanisms : namely, dragging and pulling. Successful dragging presupposes visual orientation as it involves reversal of the ant's alignment with respect to the homing direction. Pulling is compatible with preponderantly olfactory and tactile tracking. In Formica lugubris disordered movement by a number of collaborat. ing ants is followed by a pause of several minutes before rapid and orderly concerted movement towards the nest occurs. The middle pause of no movement seems to be a state of equilibrium.

J. B. Froe (Rothamsted) returned to the orchard with a study on "The Foraging of Honeybees in Fruit Orchards" and showed that nectar gatherers, especially those that stand on the petals, do not touch the stigma and thus fail to pollinate although they may receive pollen from flowers with spreading stamens such as apricot, peach, pear and plum. On some apple varieties with stiff, upright stamens no pollen is transforred to the nectar gatherer. Feeding with sugar syrup switches a greater proportion of foragers to pollen collecting and thus increases the chances of successful pollination. Bees keep to a row of trees and change to trees nearest to those initially collected from. This is of importance for maximum fruit set in trees needing cross-pollination and points to an optimal pattern of arrangement of varieties in apple orchards. As bees tend to forage near their homes, especially in unfavourable weather, colonies should be sited in small groups each near the centre of the area to be pollinated. Colonies should not be taken to the orchard until flowering has begun, as bees will not readily change to the fruit blossoms after having collected from other plants.

The rest of the first day was devoted to lower vertebrates. L. de Ruiter (Zoology Laboratory, Groningen) gave a paper on "The Feeding and Foraging in the Stickleback: Causes and Consequences" in which he demonstrated the factors involving visual feeding under quantitatively controlled conditions, and J. S. Kenny (Department of Zoology, Birkbeck Collego, London) gave an account of "A Typical Use of the Ciliary Feeding Mechanism in Some Anuran Larvæ" in various ecological niches. The primary feeding mechanism involves the buccal rasp, filters and mucus string aggregation and transport of particles by ciliary action. Mid-water and surfacefeeders may show modification in the primary mechanism such as increase in filtering area and loss of the buccal rasp. Secondary adaptations of tail and lips were also described.

The second day of the symposium, devoted entirely to bird behaviour, opened with a paper by P. M. Driver (Department of Extra-Mural Studies, Bristol) on "The Development of Feeding Mechanisms in Mergini", followed by an account by Janet Kear (The Wild Fowl Trust, Slimbridge) on the "Parental Feeding Behaviour in the Anatidae". True ducks scarcely ever foed their young, but in Anseranas, Dendrocygna and Cygnus parental feeding is well established. The development of parental feeding may start with the young feeding on surplus food falling from the bill of the parent. This is supported by innate pecking upwards of nowly hatched anatids towards the tip of pointed objects, including the bills of siblings and parents. In the magpie goose, begging and the brightly coloured head of the goslings act as releasers for parental feeding. "The Feeding Behaviour of the Wood-pigeon" was analysed by R. K. Murton (Field Research Laboratory, Worplesdon, Surrey). When food supplies are limited Columba palumbus feeds gregariously and 95 per cent of the food is made up of clover leaves. The birds feed almost continuously and selectively. The importance of a 'specific search image' was demonstrated. The speed of searching is correlated with food density. The prime function of flocking is to maintain a maximum population size where random distribution of birds without competition leads to excessive mortality.

D. J. McFerland (Institute of Experimental Psychology, Oxford) reported on "Some Interactions of Feeding and Drinking Behaviour in the Barbary Dove". These birds eat less when thirsty and drink less when hungry. This was held to be the consequence of an antagonism between the hypothalamic feeding and drinking systems. In a Skinner box thirsty birds go on working for food but do not eat it (displacement feeding ?). It appears that the food deficiency incurred in thirsty doves is capable of activating the relevant appetitive behaviour despite the fact that the birds are unable to eat the food which they obtain in this way.

In the afternoon those attending the symposium were given an opportunity to visit the Zoo and the Granada Television Film Unit and to see there a preview of unedited film material, including a fascinating close-up colour film of cobbler ants at work building their nests from leaves sewn together with the silk produced from the silk glands of their larvæ.

In a paper not originally included in the programme of the third (day which was devoted to mammalian behaviour) J. A. Chmurzyński (Nencki Institate of Experimental Biology, Warsaw) described "The Stages in the Spatial Orientation of the Digger Wasp, Bembex rostrata L.". There are three stages of spatial orientation: distant orientation outside and within the life-range (about $\frac{1}{2} \mathrm{~km}$ from the nest) with random and chiefly visual orientation respectively; proximal orientation (about $4 \mathrm{~m}$ from the nost depending on frequency and distinctiveness of natural landmarks-here visual and olfactory senses guide the orientation and recognition; "immediate orientation" (not more than $6 \mathrm{~cm}$ from the nest) when the insect finds the nest by making use chiefly of tactile clues. Three papers on various aspects of feeding in ruminants by A. Brownlee (Agricultural Research Council Institute for Research on Animal Diseases, Compton, Newbury), C. C. Balch and R. C. Campling (National Institute for Research in Dairying, Shinfield, Reading) and D. T. Chambers (Grassland Research Institute, Hurley) dealt with rumen development as related to food regimen, with the rate of eating and relative length of periods of ruminating in relation to different kinds of food, and with selective grazing habits of cattle and the associated problem of wastage respectively. A. J. B. Rudge (Infestation Control Laboratory, Guildford) reported on a preliminary investigation into baiting of wild rabbits. Whole carrots were shown to be a most suitable form of unpoisoned bait. P. R. Wiepkema (Zoological Laboratory, Groningen) spoke on the physiological significance of feeding-patterns in mice. Hyperphagia, aphagia and finickiness are considered in their relation to lesions in the ventro-median nucleus of the hypothalmus. Perception of food quality activates a hunger system which in turn stimulates a motoric eating centre. After food uptake three negative feed-back channols can be distinguished, namely, a stomach factor, a blood glucoso factor and a body-fat factor. Thoy sum up into a satiety system which inhibits the hunger system. The probable effects of ventro-median lesions on these feed-back systems were discussed.

"The Ethology of Food Hoarding in Mammals" was discussed by M. Lyall-Watson (Zoological Society of London). He gave a comprehensive survey of the different methods utilized by mammals in accumulating stores of food. Larder hoarding and scatter hoarding can be distinguished and related to seasonal requirements and 
types of food. The scattor hoarding in South American green acouchi, Myoprocta pratti, was subjected to a closer ethological analysis.

The symposium closed with an analysis of "The Aetiology of Food Reward in Monkeys" by L. Weiskrantz (Psychological Laboratory, Cambridge) and a paper on "Chimpanzee Behaviour in Relation to the Predominant Food Sources" in which V. Reynolds (London) described the overall pattern of chimpanzee activity as an alternation between convergence on areas with plentiful food and scattering when food is scarcer. This lead to optimal exploitation. The loose social structure of chimpanzees who live in bands of ever-changing size and composition may be considered to be an adaptation to the type of food distribution.

The topics discussed at this symposium clearly belonged to the borderland between ecology, horticulture, husbandry, physiology and ethology, and, although behavioural aspects were frequently not in the foreground, the meeting served the useful purpose of cross-fertilization during lively and informative discussions.

O. LowENSTEIN

\title{
IONOSPHERIC EFFECTS DUE TO THE EARTH'S ORBITAL POSITION
}

\author{
By Dr. G. NOCl
}

Osservatorio Astrofisico di Arcetri, Florence, Italy

IN the article by Sir Edward Appleton on "Ionospheric 1 Consequences of the Earth's Orbital Eccentricity"1 it was shown how the peak electrons number present in 1 $\mathrm{cm}^{3}$ of the $E$ ionospheric layer $\left(N_{m}(E)\right)$ changes during the year according to the variation of the distance of the Earth from the Sun. In Fig. 1 of Appleton's article (Fig. $\mathbf{l}(a)$ of this paper) is shown a graph obtained by working on the results of ionospheric soundings performed during $1949-59$ by several stations and leaving out all effects due to the variation of the solar activity $(R)$ and to the variation of the zenithal distance $(\chi)$ in the places of observations; on the whole this result must be considered valid for $R=$ constant and $\chi=0$.

Going from the perihelion to the aphelion, that is from the beginning of January towards the beginning of July, the distance between Earth and Sun $(r)$ changes of $\mathbf{3 \cdot 4}$ per cent; this means a variation of the solar flux of 6.5 per cent during this interval. Such value is in good agreement with the experimental one shown in Fig. I of Appleton's article if we assume the electronic density $\left(N_{m}(E)\right)$ proportional to the flux of the ionizing radiation $(q)$ (electrons loss described by an attachment law). There is still a difference of 1 per cent between the variation of $q$ and that of $N_{m}(E)$ to be explained: according to Apploton this is due to an unknown cause.

In this article I would like to show how the discrepancy between theoretical values and results is not only due to this difference-- even in the hypothesis of an attachment law for the electrons - and to explain its cause.

In the curve of Appleton's Fig. 1 the width of the concavity is too small compared with the curve showing the behaviour of $1 / r^{2}$ : in fact, if ' $a$ ' is the length of the major semi-axis of the Earth orbit, it can be easily seen

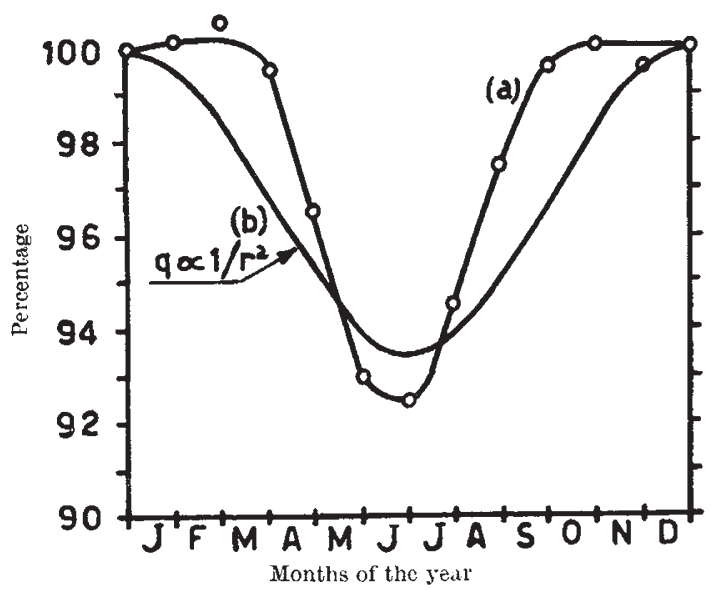

Fig. 1. Comparison between $N m(E)$ (curve $a$ ) and the solar flux supposed proportional to $1 / r^{2}$ (curve $b$ )

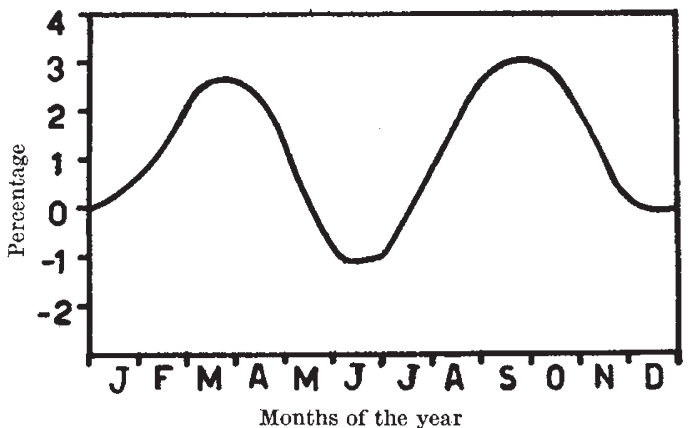

Fig. 2. Difference between the curves $(a)$ and $(b)$ of Fig. 1; that is, annual variation of the $E$ layer electron concentration due to that part of the ionizing flux which is not proportional to $r^{-2}$

that the average between the upper and the lower limits of the function $1 / r^{2}$ is larger than $1 / a^{2}$. Besides, the arc of the ellipse made by the Earth from the perihelion to the instant in which $r=a$ (and naturally $1 / r^{2}=1 / a^{2}$ ) is equal-for well-known properties of the ellipse-to a

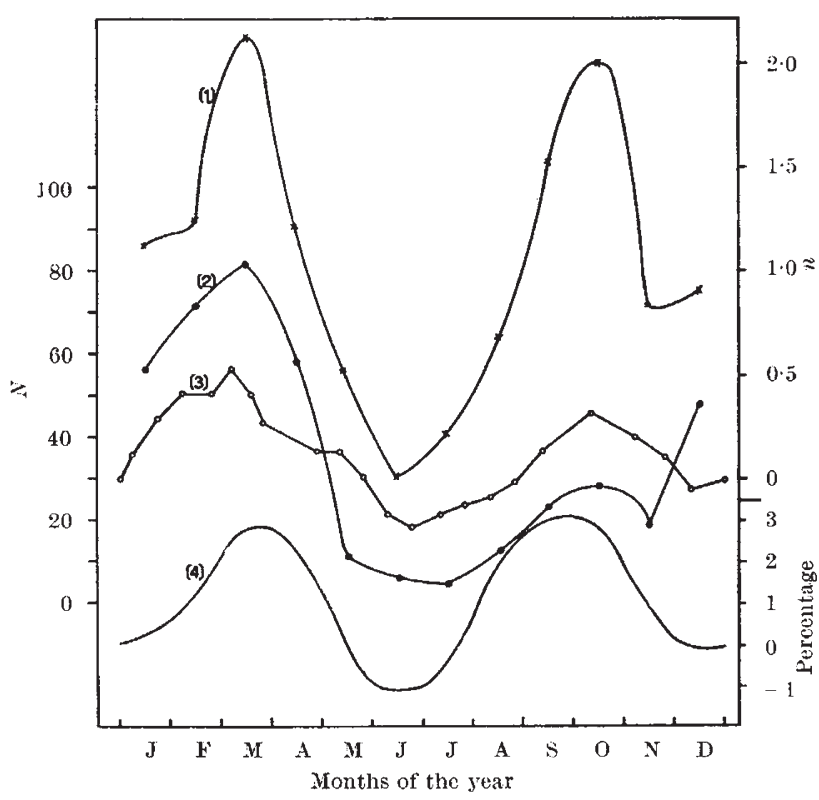

Fig. 3. (1) Annual variation of the number of nights with auroræ in Denmark (ref. 2) during 1897-1937 (scale on the right top). (2) Annual variation of the number of nights with zodiacal light (ref. 3) during $1847-1875$, according to Heision of the number of magnetic perturbations in paris ( 1923 (scale on the lent. (4) Annual variation of the 'residual peak 